\title{
Whole blood RNA offers a rapid, comprehensive approach to genetic diagnosis of cardiovascular diseases
}

\author{
Todd E. Miller, PhD ${ }^{1,4}$, Lijing You, $M S^{1}$, Robert J. Myerburg, $M D^{1}$, Paul J. Benke, $M D, P h D^{2}$,
} and Nanette H. Bishopric, MD, FACC, FAHA ${ }^{1,2,3}$

\begin{abstract}
Purpose: Long QT Syndrome, Marfan Syndrome, hypertrophic and dilated cardiomyopathy are caused by mutations in large, multi-exon genes that are principally expressed in cardiovascular tissues. Genetic testing for these disorders is labor-intensive and expensive. We sought to develop a more rapid, comprehensive, and cost-effective approach. Methods: Paired whole blood samples were collected into tubes with or without an RNA-preserving solution, and harvested for whole blood RNA or leukocyte DNA, respectively. Large overlapping CDNA fragments from KCNQ1 and KCNH2 (Long QT Syndrome), MYBPC3 (hypertrophic and dilated cardiomyopathy), or FBN1 (Marfan Syndrome) were amplified from RNA and directly sequenced. Variants were confirmed in leukocyte DNA. Results: All 4 transcripts were amplified and sequenced from whole blood mRNA. Six known and 2 novel mutations were first identified from RNA of 10 probands, and later confirmed in genomic DNA, at considerable savings in time and cost. In one patient with MFS, RNA sequencing directly identified a splicing mutation. Results from RNA and DNA were concordant for single nucleotide polymorphisms at the same loci. Conclusion: Taking advantage of new whole blood RNA stabilization methods, we have designed a cost-effective, comprehensive method for mutation detection that should significantly facilitate clinical genetic testing in four lethal cardiovascular disorders. Genet Med 2007:9(1):23-33.
\end{abstract}

Key Words: Genetic testing, cardiomyopathy, sudden death, fibrillin-1, PaxGene genetic testing, cardiomyopathy, sudden death, fibrillin-1, PaxGene

Many forms of heart disease have a genetic basis. ${ }^{1}$ The clinical value of screening for many of these disorders is well established, ${ }^{2,3}$ offering opportunities for pre-symptomatic intervention, parental counseling, and risk stratification. Unfortunately, access to genetic testing in cardiac diseases is limited by several factors. First, many of these disorders are recognized only in adulthood, reducing diagnostic suspicion for heritable disease, as well as limiting opportunities for gene identification through linkage analysis, since family members are often unavailable for testing. A second major problem is access: many of the tests are costly and labor-intensive, and only a few laboratories offer testing.

There are multiple technical reasons for this lack of access. Many cardiovascular disorders are caused by multiple mutations in very large genes, with mutations distributed through-

From the ${ }^{1}$ Departments of Medicine, Division of Cardiology, ${ }^{2}$ Molecular and Cellular Pharmacology, and ${ }^{3}$ Pediatrics, Miller School of Medicine, University of Miami, Miami, Florida; ${ }^{4}$ Currently associated with Specialty Laboratories, Valencia, California.

Nanette H. Bishopric, MD, FACC, FAHA, Professor of Pharmacology, Medicine and Pediatrics Department of Molecular and Cellular Pharmacology (R-189), Miller School of Medicine, University of Miami, PO Box 016189 (R-189), Miami, FL 33101.E-mail: n.bishopric@ miami.edu or Todd E. Miller, PhD, Specialty Laboratories, 27027 Tourney Road, Valencia, CA 91355.E-mail: Tmillerl@specialtylabs.com

Submitted for publication October 4, 2006.

Accepted for publication October 30, 2006.

DOI: 10.1097/GIM.0b013e31802d74de out their length. For example, Marfan Syndrome (MFS) is associated with over 600 mutations throughout the 65-exon fibrillin-1 (FBN1) gene. ${ }^{4}$ Long QT Syndrome is linked to more than 300 individual mutations in 7 different genes that together include over 70 exons; no single mutation accounts for a significant proportion of cases. ${ }^{3,5-8}$ Hypertrophic cardiomyopathy (HCM) is caused by one of nearly 200 mutations in at least 10 genes encoding sarcomeric proteins; dilated cardiomyopathy $(\mathrm{DCM})$ is associated with mutations in 16 different genes, and these account for only a fraction of familial instances of the disease. ${ }^{9,10}$ Thus, high-throughput solutions such as microsphere assays are not feasible and/or would miss a large number of new mutations. Common approaches are therefore either brute force sequencing of all exons amplified from lymphocyte genomic DNA, or screening of the exons using a chromatographic method (e.g. single strand conformation polymorphism (SSCP) or denaturing high-performance liquid chromatography (DHPLC)) followed by sequencing of exons with abnormal mobility. ${ }^{3,6,11,12}$ These tests are rarely covered by insurance, and the cost and effort associated with either strategy prices them out of reach for most patients.

An alternative solution to these difficulties is to sequence the messenger RNA (mRNA) encoded by these genes. Because mRNA is processed to remove most noncoding sequences, the amount of genetic material to be tested is available in larger fragments that can be efficiently analyzed by direct sequencing. 
Genetic testing for cardiovascular diseases could thus be greatly facilitated by mRNA-based screening. However, use of mRNA has traditionally required substantial additional cost, resources and time. Because of their accessibility, peripheral blood leukocytes or fibroblasts are preferred sources of mRNA, but in order to obtain sufficient material for genetic testing these cells must be purified or expanded in culture, sometimes with the assistance of immortalizing viruses. Another limitation is that the gene of interest must be transcribed at detectable levels in available tissue samples. This can be a particular problem for cardiac-restricted genes, since myocardial tissue from the proband is usually unavailable. Ectopic transcription has been noted for a number of genes ${ }^{13}$ and "leaky" expression of the HCM-linked genes beta myosin heavy chain (MYH7), cardiac troponin $\mathrm{T}$ (TNNT2), and MYBPC3 in lymphocytes ${ }^{14,}$ 15,16 has not proven robust enough to serve as a source of genetic testing material.

In the last two years, the demand for microarray-based gene expression analysis ${ }^{17,18}$ has driven the development of new methods for harvesting and preserving RNA. To date, these methods have not been exploited for genetic testing, although their potential is clear. Here we describe the incorporation of improved RNA purification technology into a genetic screening method that permits RNA amplification and direct sequencing of cardiovascular disease-associated genes from $<3$ $\mathrm{mL}$ of unfractionated peripheral blood. We show that whole blood RNA is a robust, efficient and considerably less expensive source of sequence information compared with RNA from expanded or immortalized cell sources. Finally, we demonstrate the utility of the method by detecting 2 novel and 6 previously reported disease-causing mutations in 4 cardiovascular disease-associated genes, from 10 prospectively tested probands referred for genetic testing of LQTS, MFS and HCM. We propose the use of RNA from unfractionated blood as part of a rapid and simple method for screening mutations in complex cardiovascular genetic disorders.

\section{METHODS}

\section{Human subjects}

Subjects were recruited and evaluated in accordance with regulations set forth by the University of Miami Committee for the Protection of Human Subjects and under human subjects research protocols approved by the UM Institutional Review Board. Informed consent was obtained from all blood donors, including those providing control samples.

\section{Preparation of nucleic acids}

Genomic DNA was prepared from peripheral blood lymphocytes with the Puregene DNA Isolation kit (Gentra Systems, Inc., Minneapolis, MN), according to the manufacturer's recommendation. RNA was prepared from $2.5 \mathrm{~mL}$ of whole peripheral blood collected into PAXgene blood collection tubes, containing a mixture of quaternary amine surfactants (PAXgene Blood RNA Validation kit, Qiagen, Inc., Valencia, CA). Blood samples were stored at $4^{\circ} \mathrm{C}$ and processed within 4 days of collection according to the manufacturer's instructions. Of note, both the PAXgene Blood RNA Validation Kit and Versagene RNA purification kit (Gentra Systems) worked well in this application; the PAXgene protocol is given here. In brief, after warming for 2 hours to room temperature, the tubes were centrifuged for 10 minutes at $3,000 \mathrm{~g}$, and the supernatant decanted. The pellet was rinsed in $5 \mathrm{~mL}$ RNasefree water, and then re-suspended in $360 \mu \mathrm{L}$ of buffer BR1 by vortexing. The pellet was then digested by addition of $300 \mu \mathrm{L}$ BR2 lysis buffer and $40 \mu \mathrm{L}$ proteinase $\mathrm{K}$ solution, vortexing and incubation at $55^{\circ} \mathrm{C}$ for 10 minutes, and centrifugation for 3 minutes at $16,000 \mathrm{~g}$. Supernatants were carefully pipetted into RNase-free microcentrifuge tubes, mixed with $350 \mu \mathrm{L}$ of $100 \%$ ethanol, and applied to PAXgene Blood RNA Kit spin columns. Columns were centrifuged at $10,000 \mathrm{~g}$ for 1 minute and the flow-through discarded. Bound RNA was then washed with $350 \mu \mathrm{L}$ of buffer BR3, centrifuged at $16,000 \mathrm{~g}$, and digested for 15 minutes at room temperature with $80 \mu \mathrm{L}$ DNase (RNase-free DNase, Qiagen). Samples were washed once with $350 \mu \mathrm{L}$ of BR3 and twice with $500 \mu \mathrm{L}$ of BR4. RNA was then eluted with 2 successive applications of $40 \mu \mathrm{L}$ of buffer BR5, denatured at $65^{\circ} \mathrm{C}$ for 5 minutes and then either processed immediately or stored at $-80^{\circ} \mathrm{C}$. Nucleic acid concentrations were determined by UV absorption.

\section{Reverse transcription and PCR}

Reverse transcription was done in a $20-\mu \mathrm{L}$ reaction using either cloned M-MLV RTase (Ambion, Inc., Austin, TX), or Transcriptor RTase (Roche Applied Science, Indianapolis, IN), according to the manufacturer's recommendations. Random hexamers were used as primers for each enzyme. Firstround PCR was performed in a $25-\mu \mathrm{L}$ reaction containing 2 $\mu \mathrm{L}$ of an RTase reaction as template, $1 \mu \mathrm{M}$ each primer, 1.5 $\mathrm{mM} \mathrm{MgCl} 2,250 \mu \mathrm{M}$ each dNTP, $1 \mathrm{M}$ betaine, $1 \times$ reaction buffer, and 1 unit of Taq polymerase (Continental Lab Products, San Diego, CA). When needed, second-round PCR was performed using nested primers, $2 \mu \mathrm{L}$ of the first round PCR as a template, and otherwise identical ingredients. The primers and PCR conditions are shown in Table 1. Primers were designed using VectorNTI software (Invitrogen Corp., Carlsbad, CA).

\section{DNA sequencing}

PCR products were purified using a Qiaquick PCR Purification Kit (Qiagen). Purified products were quantified by gel electrophoresis, and used with reagents from Applied Biosystems, Inc. (ABI), in cycle sequencing reactions. These products were then resolved on an ABI 3100 Genetic Analyzer, and analyzed using ABI Sequence Analysis software. Reference sequences were obtained from Genbank and are listed in Table 1.

\section{Concordance and allele expression analysis}

To establish that RNA amplification detected both alleles, and that genotypes from RNA and DNA were concordant, we sought to detect common heterozygous single nucleotide polymorphisms (SNPs) from each of the genes tested in 
Table 1

Primers and PCR conditions for blood RNA amplification

Primer sequences

\begin{tabular}{lll}
\hline PCR & Primer & Sequence \\
\hline
\end{tabular}

KCNQ1, KVLQT1, LQT1 (Genbank NM 000218, numbered 1-2031, ATG to stop) ${ }^{a}$

$\begin{array}{ll}\text { A } & \text { LQT1-210S } \\ \text { A } & \text { LQT1-1312A } \\ \text { B } & \text { LQT1-1105S } \\ \text { B } & \text { LQT1-2382A }\end{array}$

CGCCGCGCCCCCAGTTGC

GCATCTTCTCTCCAGGAGT

201-1312, 1102 bp

CCGGCGGCAGCCTCACTCA

CCAAGCTTGGTAACAACTCA

GACCTGAGAC

$1105-2382,1277 \mathrm{bp}$

KCNH2, HERG, LQT2 (Genbank NM 000238, numbered 1-3480, ATG to stop)

$\begin{array}{ll}\text { A } & \text { LQT2-40S } \\ \text { A } & \text { LQT2-1258A } \\ \text { B } & \text { LQT2-1075S } \\ \text { B } & \text { LQT2-2291A } \\ \text { C } & \text { LQT2-2100S } \\ \text { C } & \text { LQT2-3602A }\end{array}$

GCCGCAGAACACCTTCCTGGACA

CAGGATGAGCCAGTCCCACACGG

40-1258, 1219 bp

TGACCGTGAGATCATAGCACCTAAGAT AAAGG

TCTTGAACTTCATGGCCAGGGCC

$1075-2291,1217$ bp

GCCTCGAGGAGTACTTCCAGCACG

TTCCTCTCCCCTTCCACGGTCAG

2100-3602, 1503 bp

MYBPC3 (Genbank NM 000256, numbered 1-3825, ATG to stop)

$\begin{array}{ll}\text { A } & \text { MBPC(-19S) } \\ \text { A } & \text { MBPC-1645A } \\ \text { A1 } & \text { MBPC-23S } \\ \text { A1 } & \text { MBPC-1016A } \\ \text { A2 } & \text { MBPC-891S } \\ \text { A2 } & \text { MBPC-1557A } \\ \text { B } & \text { MBPC-1353S } \\ \text { B } & \text { MBPC-2612A } \\ \text { B1 } & \text { MBPC-1471S } \\ \text { B1 } & \text { MBPC-2567A } \\ \text { C } & \text { MBPC-2421S } \\ \text { C } & \text { MBPC-3897A } \\ \text { C1 } & \text { MBPC-2504S } \\ \text { C1 } & \text { MBPC-3778A }\end{array}$

\section{TGGTGTGACGTCTCTCAGGATGCC}

GGTACACCTCCAGCTTCTTTTCCTGC

$-19-1645,1663 \mathrm{bp}$

CAGTCTCAGCCTTTAGCAAGAAGCCA

TGGAAGGCGATGCGCTCGTA

23-1016, $993 \mathrm{bp}$

ACTGCTGAAAAAGAGAGACAGTTTCCGG

CAGCATGGCCTCGTTGATGATCA

891-1557, 666 bp

GCCCCCTGTGCTCATCACGC

CTGGGGGGACCGATAGGCATG

1353-2612, 1259 bp

GTGGAGCTGACCCGGGAGGAGA

CCTGGACATGCCGATGGCGT

1471-2567, 1096 bp

CCTGGAGCGCAAGAAGAAGAAGAGCTACC

CAACTTCCCTCCAGGCTCCTGGCA

2421-3897, 1476 bp

GCATGATCGAGGGCGTGGTGTACG

CCTGTAAGTTGGTGGCCCTGCAGACATAG

2504-3778, 1274 bp

FBN1 (Genbank NM 000138, numbered 1-8616, ATG to stop)

$\begin{array}{ll}\text { A } & \text { FB-116S } \\ \text { A } & \text { FB-1595A } \\ \text { A1 } & \text { FB-129S } \\ \text { A1 } & \text { FB-1556A } \\ \text { B } & \text { FB-1412S } \\ \text { B } & \text { FB-2581A } \\ \text { B1 } & \text { FB-1454S } \\ \text { B1 } & \text { FB-2513A } \\ \text { C } & \text { FB-2341S } \\ \text { C } & \text { FB-3972A } \\ \text { C1 } & \text { FB-2382S }\end{array}$

CGGTGGCGGCTCGGCATCAT

ACTCCCCACGGAGGTCCAGCTGG

$-18-1462,1479$ bp

GCATCATGCGTCGAGGGCGT

CACACCGGCAACTCCCAGGAGT

$-5-1423,1427$ bp

GTCCCTCGACCACCAGTGGAATATCT

GCAAGGACTTGATTCGCATTCATCA

$1279-2448,1169$ bp

CCACCAAGGGTGCTGCCAGTAA

TGGGGCAGGTACAGACAAAACTTCC

$1321-2380,1059$ bp

TGGAATCTGTGAAAACCTTCGTGGG

TCTACACAAGTCTTCATGTCTTCAGATGCC

2208-3839, 1631 bp

GCAATTCAGGATATGAAGTGGATTCAACTG

(Continued) 
Table 1

Continued

Primer sequences

\begin{tabular}{|c|c|c|c|}
\hline PCR & Primer & Sequence & Region amplified \\
\hline $\mathrm{C} 1$ & FB-3906A & GGGATATTTGTGCACTGACCACCATC & 2249-3773, 1524 bp \\
\hline $\mathrm{D}$ & FB-3785S & AGCTATGAATGTAGCTGTCAGCCGGG & \\
\hline $\mathrm{D}$ & FB-5483A & TGATACACACTCCATTTTCACAGACCCC & $3652-5350,1698$ bp \\
\hline D1 & FB-3825S & CTGACCAGAGATCATGCACCGACA & \\
\hline D1 & FB-5417A & CGGTATAAATGTCGATGACAAAGCCTG & $3692-5284,1592$ bp \\
\hline $\mathrm{E}$ & FB-5300S & TACAACATTGGCCGGGCGTGG & \\
\hline $\mathrm{E}$ & FB-7067A & CACGGGTGTTGAGGCAGCGC & $5167-6934,1767$ bp \\
\hline E1 & FB-5342S & CCCATCCCAAGTACAGATGAGTTTGC & \\
\hline E1 & FB-7002A & ACACAGCCTTCTCCATCAGGTCTCC & $5209-6869,1660$ bp \\
\hline $\mathrm{F}$ & FB-6825S & AATGTCCCGTGGGATATGTGCTCA & \\
\hline $\mathrm{F}$ & FB-7790A & GGCATTCACAGGTGAAGCTTCCAG & $6692-7657,965$ bp \\
\hline F1 & FB-6850S & AGAAGACCGTAGGATGTGCAAAGATGA & \\
\hline $\mathrm{F} 1$ & FB-7739A & CGCACAGATTGATGTCAGAGGTGC & $6717-7606,889 \mathrm{bp}$ \\
\hline G & FB-7642S & CATTGGCGGCTTCACATGCAAA & \\
\hline G & FB-8831A & TGATGATTCTGATTGGGGGAAAATATAGTT & \\
\hline G1 & FB-7670S & CCGGATTTACCCAACACCATACG & \\
\hline G1 & FB-8766A & GGTCTCTGGATGGTGAATTAATGAAGC & $7537-8633,1096$ bp \\
\hline & & PCR conditions & \\
\hline
\end{tabular}

\begin{tabular}{|c|c|c|c|c|c|}
\hline PCR & Initial denaturation & Denaturation & Annealing & Polymerization & Number of cycles \\
\hline \multicolumn{6}{|l|}{ KCNQ1 } \\
\hline$A$ and $B$ & $4 \min , 94^{\circ} \mathrm{C}$ & $30 \mathrm{sec}, 94^{\circ} \mathrm{C}$ & $30 \mathrm{sec}, 65^{\circ} \mathrm{C}$ & $70 \mathrm{sec}, 72^{\circ} \mathrm{C}$ & 3535 \\
\hline \multicolumn{6}{|l|}{$\mathrm{KCNH} 2$} \\
\hline $\mathrm{A}, \mathrm{B}$ and $\mathrm{C}$ & $4 \min , 94^{\circ} \mathrm{C}$ & $30 \mathrm{sec}, 94^{\circ} \mathrm{C}$ & $20 \mathrm{sec}, 62^{\circ} \mathrm{C}$ & $60 \mathrm{sec}, 72^{\circ} \mathrm{C}$ & \\
\hline \multicolumn{6}{|l|}{ MYBPC3 } \\
\hline A & $4 \mathrm{~min}, 94^{\circ} \mathrm{C}$ & $30 \mathrm{sec}, 94^{\circ} \mathrm{C}$ & $30 \mathrm{sec}, 61^{\circ} \mathrm{C}$ & $80 \mathrm{sec}, 72^{\circ} \mathrm{C}$ & 35 \\
\hline $\mathrm{A} 1$ & $4 \mathrm{~min}, 94^{\circ} \mathrm{C}$ & $30 \mathrm{sec}, 94^{\circ} \mathrm{C}$ & $30 \mathrm{sec}, 61^{\circ} \mathrm{C}$ & $50 \mathrm{sec}, 72^{\circ} \mathrm{C}$ & 35 \\
\hline $\mathrm{A} 2$ & $4 \min , 94^{\circ} \mathrm{C}$ & $30 \mathrm{sec}, 94^{\circ} \mathrm{C}$ & $30 \mathrm{sec}, 61^{\circ} \mathrm{C}$ & $50 \mathrm{sec}, 72^{\circ} \mathrm{C}$ & 35 \\
\hline B & $4 \min , 94^{\circ} \mathrm{C}$ & $30 \mathrm{sec}, 94^{\circ} \mathrm{C}$ & $30 \mathrm{sec}, 62^{\circ} \mathrm{C}$ & $60 \mathrm{sec}, 72^{\circ} \mathrm{C}$ & 35 \\
\hline B1 & $4 \min , 94^{\circ} \mathrm{C}$ & $30 \mathrm{sec}, 94^{\circ} \mathrm{C}$ & $30 \mathrm{sec}, 62^{\circ} \mathrm{C}$ & $60 \mathrm{sec}, 72^{\circ} \mathrm{C}$ & 35 \\
\hline $\mathrm{C}$ & $4 \min , 94^{\circ} \mathrm{C}$ & $30 \mathrm{sec}, 94^{\circ} \mathrm{C}$ & $30 \mathrm{sec}, 65^{\circ} \mathrm{C}$ & $90 \mathrm{sec}, 72^{\circ} \mathrm{C}$ & 35 \\
\hline $\mathrm{C} 1$ & $4 \mathrm{~min}, 94^{\circ} \mathrm{C}$ & $30 \mathrm{sec}, 94^{\circ} \mathrm{C}$ & $30 \mathrm{sec}, 65^{\circ} \mathrm{C}$ & $70 \mathrm{sec}, 72^{\circ} \mathrm{C}$ & 35 \\
\hline \multicolumn{6}{|l|}{ FBN1 } \\
\hline A & $4 \min , 94^{\circ} \mathrm{C}$ & $30 \mathrm{sec}, 94^{\circ} \mathrm{C}$ & $20 \mathrm{sec}, 65^{\circ} \mathrm{C}$ & $60 \mathrm{sec}, 72^{\circ} \mathrm{C}$ & 35 \\
\hline $\mathrm{Al}$ & $4 \mathrm{~min}, 94^{\circ} \mathrm{C}$ & $30 \mathrm{sec}, 94^{\circ} \mathrm{C}$ & $20 \mathrm{sec}, 65^{\circ} \mathrm{C}$ & $60 \mathrm{sec}, 72^{\circ} \mathrm{C}$ & 35 \\
\hline B & $4 \min , 94^{\circ} \mathrm{C}$ & $30 \mathrm{sec}, 94^{\circ} \mathrm{C}$ & $20 \mathrm{sec}, 65^{\circ} \mathrm{C}$ & $60 \mathrm{sec}, 72^{\circ} \mathrm{C}$ & 35 \\
\hline B1 & $4 \mathrm{~min}, 94^{\circ} \mathrm{C}$ & $30 \mathrm{sec}, 94^{\circ} \mathrm{C}$ & $20 \mathrm{sec}, 65^{\circ} \mathrm{C}$ & $60 \mathrm{sec}, 72^{\circ} \mathrm{C}$ & 35 \\
\hline $\mathrm{C}$ & $4 \mathrm{~min}, 94^{\circ} \mathrm{C}$ & $30 \mathrm{sec}, 94^{\circ} \mathrm{C}$ & $20 \mathrm{sec}, 65^{\circ} \mathrm{C}$ & $60 \mathrm{sec}, 72^{\circ} \mathrm{C}$ & 35 \\
\hline $\mathrm{C} 1$ & $4 \min , 94^{\circ} \mathrm{C}$ & $30 \mathrm{sec}, 94^{\circ} \mathrm{C}$ & $20 \mathrm{sec}, 65^{\circ} \mathrm{C}$ & $60 \mathrm{sec}, 72^{\circ} \mathrm{C}$ & 35 \\
\hline $\mathrm{D}$ & $4 \mathrm{~min}, 94^{\circ} \mathrm{C}$ & $30 \mathrm{sec}, 94^{\circ} \mathrm{C}$ & $20 \mathrm{sec}, 65^{\circ} \mathrm{C}$ & $60 \mathrm{sec}, 72^{\circ} \mathrm{C}$ & 35 \\
\hline D1 & $4 \min , 94^{\circ} \mathrm{C}$ & $30 \mathrm{sec}, 94^{\circ} \mathrm{C}$ & $20 \mathrm{sec}, 65^{\circ} \mathrm{C}$ & $60 \mathrm{sec}, 72^{\circ} \mathrm{C}$ & 35 \\
\hline & & & & & (Continued) \\
\hline
\end{tabular}


Table 1

Continued

PCR conditions

\begin{tabular}{|c|c|c|c|c|c|}
\hline PCR & Initial denaturation & Denaturation & Annealing & Polymerization & Number of cycles \\
\hline $\mathrm{E}$ & $4 \mathrm{~min}, 94^{\circ} \mathrm{C}$ & $30 \mathrm{sec}, 94^{\circ} \mathrm{C}$ & $20 \mathrm{sec}, 65^{\circ} \mathrm{C}$ & $60 \mathrm{sec}, 72^{\circ} \mathrm{C}$ & 35 \\
\hline E1 & $4 \mathrm{~min}, 94^{\circ} \mathrm{C}$ & $30 \mathrm{sec}, 94^{\circ} \mathrm{C}$ & $20 \mathrm{sec}, 65^{\circ} \mathrm{C}$ & $60 \mathrm{sec}, 72^{\circ} \mathrm{C}$ & 35 \\
\hline $\mathrm{F}$ & $4 \mathrm{~min}, 94^{\circ} \mathrm{C}$ & $30 \mathrm{sec}, 94^{\circ} \mathrm{C}$ & $20 \mathrm{sec}, 62^{\circ} \mathrm{C}$ & $60 \mathrm{sec}, 72^{\circ} \mathrm{C}$ & 35 \\
\hline $\mathrm{F} 1$ & $4 \mathrm{~min}, 94^{\circ} \mathrm{C}$ & $30 \mathrm{sec}, 94^{\circ} \mathrm{C}$ & $20 \mathrm{sec}, 62^{\circ} \mathrm{C}$ & $60 \mathrm{sec}, 72^{\circ} \mathrm{C}$ & 35 \\
\hline G & $4 \mathrm{~min}, 94^{\circ} \mathrm{C}$ & $30 \mathrm{sec}, 94^{\circ} \mathrm{C}$ & $20 \mathrm{sec}, 62^{\circ} \mathrm{C}$ & $60 \mathrm{sec}, 72^{\circ} \mathrm{C}$ & 35 \\
\hline G1 & $4 \mathrm{~min}, 94^{\circ} \mathrm{C}$ & $30 \mathrm{sec}, 94^{\circ} \mathrm{C}$ & $20 \mathrm{sec}, 62^{\circ} \mathrm{C}$ & $60 \mathrm{sec}, 72^{\circ} \mathrm{C}$ & 35 \\
\hline
\end{tabular}

${ }^{a}$ KCNQ1 and KCNH2 account for approximately $80 \%$ of known mutations in Long QT Syndrome. The primers shown here amplify all but the first 250 bp of coding sequence for KCNQ1, which has over $80 \%$ GC content and comparatively few disease-causing mutations, and which was not possible to amplify from whole blood. However this region can be readily amplified from genomic DNA in a single PCR reaction.

both RNA and DNA. The SNPs used for KCNQ1 were $1638 \mathrm{G}>\mathrm{A}$ (S546S, rs 1057128) and 1986C $>\mathrm{T}$ (Y662Y, rs11601907). For KCNH2, we used 1956T $>$ C $(Y 652 \mathrm{Y}$, rs 10226664) and 2690A $>C$ (K897T, rs1805123). For MYBPC3, a SNP with 2 common alleles in exon 31, 3288A $>$ G (E1096D, rs1052373), was used.

\section{RESULTS}

Our prospective series included 2 sets of blood samples from 14 individuals: 10 unrelated subjects referred for genotyping ( 6 suspected LQTS, 2 HCM, and 2 MFS) and 4 unaffected, unrelated controls. Table 2 provides clinical information on individual patients. Blood samples for RNA were collected directly into tubes containing quaternary ammonium surfactants (PAXgene Blood RNA Validation kit, Qiagen, Inc.), which simultaneously lyse cells and precipitate RNA. RNA was then isolated and purified using standard spin-column binding and elution methods. We routinely obtained a minimum of $5 \mu \mathrm{g}$ of RNA from $2.5 \mathrm{~mL}$ of whole blood after 2-3 hours processing time. This amount of RNA is enough to perform at least 5 reverse transcription reactions, in turn yielding enough cDNA template for at least 50 primary PCRs.

Our PCR primer pairs were designed to amplify approximately $1-1.5 \mathrm{~kb}$ segments of continuous coding sequence, and produced products of the expected size from over $90 \%$ of samples. A single round of PCR was sufficient for KCNQ1 and $K C N H 2$, while $M Y B P C 3$ and FBN1 both required a second round of nested PCR (Table 1). RNA-derived sequence data were then validated, first by comparison to the reference gene sequence in GenBank, and then by analysis of the corresponding exons from genomic DNA. These studies confirmed that we were able to amplify the major disease-associated transcripts, including the nominally tissue-restricted LQTS-associated and MYBPC3 transcripts, from whole blood RNA. Expression and amplification of both alleles were confirmed by identification of heterozygosity for previously reported or novel SNPs, or for disease-associated variants. In nearly all cases, genotypes determined from RNA and DNA were concordant.

Table 2

Characteristics of patients studied

\begin{tabular}{|c|c|c|c|c|}
\hline Patient & Age & Sex & Diagnosis & Phenotype \\
\hline 1 & $1 \mathrm{mo}$ & M & LQTS & $\mathrm{QT}_{\mathrm{c}}$ of $570 \mathrm{~ms}$ \\
\hline 2 & $15 \mathrm{mo}$ & M & LQTS & $\mathrm{QT}_{\mathrm{c}}$ of $490 \mathrm{~ms}$ \\
\hline 3 & $26 \mathrm{yr}$ & $\mathrm{F}$ & LQTS & $\mathrm{QT}_{\mathrm{c}}$ of $480 \mathrm{~ms}$, syncope, dyspnea \\
\hline 4 & $23 \mathrm{yr}$ & $\mathrm{F}$ & LQTS & $\begin{array}{l}\text { Multiple episodes of syncope after suddenly waking to a } \\
\text { noise, AICD }\end{array}$ \\
\hline 5 & $11 \mathrm{yr}$ & M & LQTS & $\mathrm{QT}_{\mathrm{c}}$ of $520 \mathrm{~ms}$, syncope/seizures \\
\hline 6 & $33 \mathrm{yr}$ & $\mathrm{F}$ & LQTS & Heart attack at age 25, AICD \\
\hline 7 & $26 \mathrm{yr}$ & M & $\mathrm{HCM}$ & Decreased exercise tolerance, IVSD of $1.9 \mathrm{~cm}$ \\
\hline 8 & $57 \mathrm{yr}$ & M & HCM & Dyspnea, IVSD of $1.3 \mathrm{~cm}$ \\
\hline 9 & $17 \mathrm{yr}$ & M & MFS & $\begin{array}{l}\text { Dental crowding, mild scoliosis, arachnodactyly, } 6^{\prime} 5^{\prime \prime} \text { tall, } \\
113 \text { pounds, positive thumb and wrist signs }\end{array}$ \\
\hline 10 & $30 \mathrm{yr}$ & M & MFS & $\begin{array}{l}\text { Pectus carinatum, arachnodactyly, aortic root of } 4.24 \mathrm{~cm} \text {, } \\
\text { father had aortic dissection at age } 40\end{array}$ \\
\hline
\end{tabular}




\section{Long QT syndrome (KCNQ1 and KCNH2)}

From 10 probands and 4 healthy controls, all 3 single-locus genotypes for $K C N Q 1$ and $K C N H 2$ were observed, and genotypes determined by RNA and DNA were completely concordant, indicating that both alleles as well as the major RNA transcripts of KCNQ1 and $K C N H 2$ are expressed and detectable in blood RNA. Our amplification strategy did not specifically detect two minor variant transcripts of KCNQ1 or $\mathrm{KCNH} 2$, each of which encodes an amino terminal truncated protein. ${ }^{19,20}$ The variant tKVLQT1 is missing nucleotides encoding the cytoplasmic domain and one-third of its first transmembrane domain, but does not contain any unique exons, hence the primer set captures all of the coding information from both isoforms. ${ }^{19}$ The HERG1b isoform replaces exons 1-5 of HERG1 with a unique 97 bp exon 1 encoding a truncated cytoplasmic domain. ${ }^{20}$ This short unique sequence would be omitted by any exon amplification strategy that did not specifically target the HERG1b-specific exon 1. To our knowledge, this region of HERG1 has not yet been implicated in LQTS.

In two out of six patients referred for LQTS genotyping, three KCNQ1 mutations were identified from blood RNA, and subsequently confirmed by DNA analysis. One proband, a male newborn with bradycardia and a QTc of 570 milliseconds, had a novel missense mutation, 1016T $>$ C (F339S). The mutation, which was not detected in either parent, occurs at the second of 8 consecutive disease-implicated residues in the S6 transmembrane region. Functional studies of this mutant channel in a Xenopus oocyte expression system indicated the channel was unable to interact normally with the KCNE1 beta subunit (unpublished data, 2005). The second proband, a 15month-old male with a QTc of 490 milliseconds, had two mutations: $430 \mathrm{~A}>\mathrm{G}(\mathrm{T} 144 \mathrm{~A})$ and $1781 \mathrm{G}>\mathrm{C}(\mathrm{R} 594 \mathrm{P})$. Figure $1 \mathrm{~A}, \mathrm{C}$ show the amplified cDNA sequence for these mutations, confirmed on subsequent DNA sequencing (Figs. 1B,D). His asymptomatic mother, who had a QTc of 460 milliseconds, harbored both mutations, suggesting that these reside on the same allele and were co-inherited. Mutations at each of these three residues have been individually associated with LQTS, although to our knowledge R594P and F339S are novel, as is the existence of T144A and a second mutation on the same

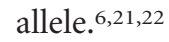

Two other patients were found to have mutations in $\mathrm{KCNH} 2$. A 23-year-old woman had been treated for seizures since falling out of bed at age 16, and at age 20 lost consciousness when a maid knocked on her hotel room door. She was subsequently diagnosed with LQTS, and given an automatic implantable cardioverter defibrillator. Whole blood RNA genotyping revealed a 1704G $>$ C mutation that was confirmed by sequencing exon 7 from genomic DNA. This creates a missense mutation, W568C, previously reported to cause LQTS 23 (Fig. 2). The second $\mathrm{KCNH} 2$ mutation was found in an 11-year-old boy who had fainted a year before while playing soccer. His mother has experienced fainting spells throughout her life, and her father had died of a heart attack at age 42. A heterozygous base, $1838 \mathrm{C}>\mathrm{T}$, was found in the $\mathrm{CDNA}$ and confirmed by sequencing exon 7 from genomic DNA. This transition mutation leads to an amino acid change, T613M, also previously reported to cause LQTS.6,21 Genetic testing of the boy's mother revealed that she was the source of his mutation.

\section{Hypertrophic cardiomyopathy (MYBPC3)}

Mutations in cardiac myosin binding protein C (MYBPC3) account for almost half the mutations associated with HCM, and $>20 \%$ of clinically diagnosed HCM cases. ${ }^{24}$ Nearly 100 mutations have been found, distributed throughout the length of the protein. We were able to successfully amplify MYBPC3 from blood RNA, using a nested PCR strategy with primers shown in Table 1. In our group of 10 probands and 4 controls, SNP analysis revealed
A
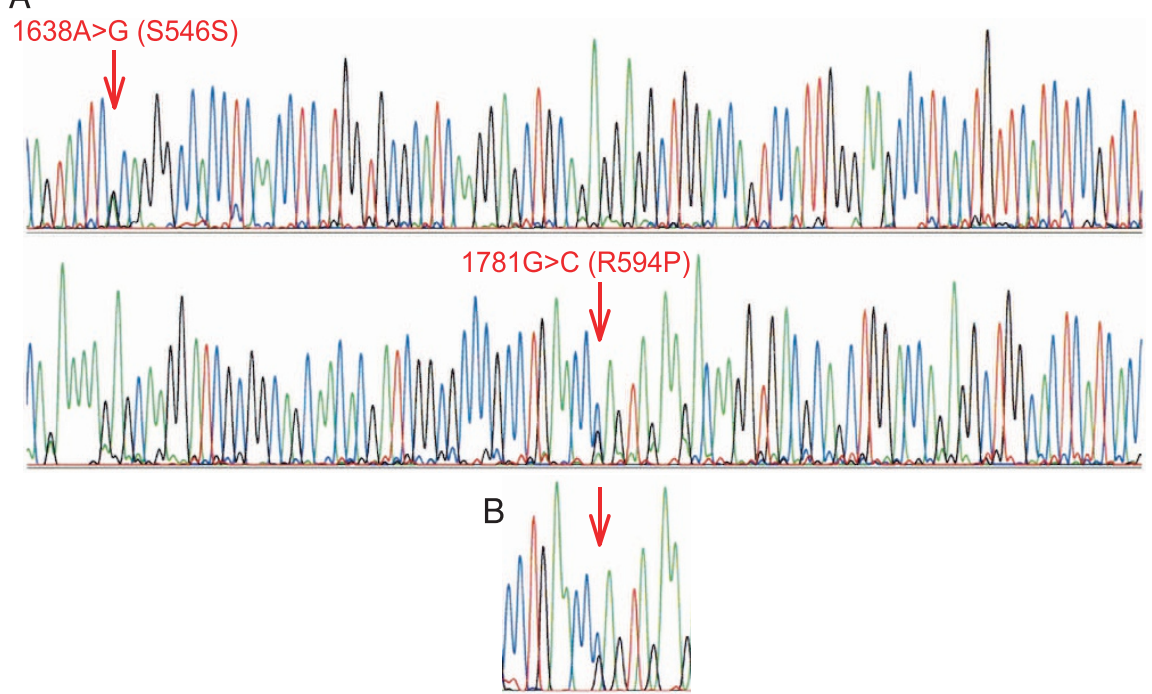

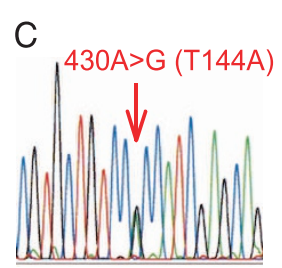

D

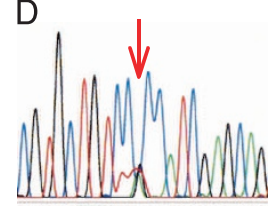

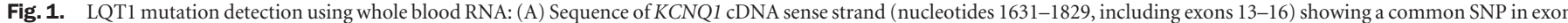

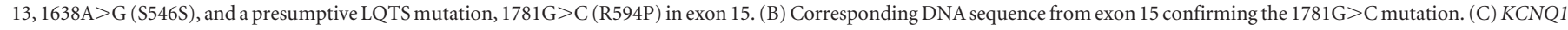
cDNA sequence showing $430 \mathrm{~A}>\mathrm{G}$ (T144A), a previously reported LQTS mutation in exon 2 and (D) corresponding genomic DNA sequence. 


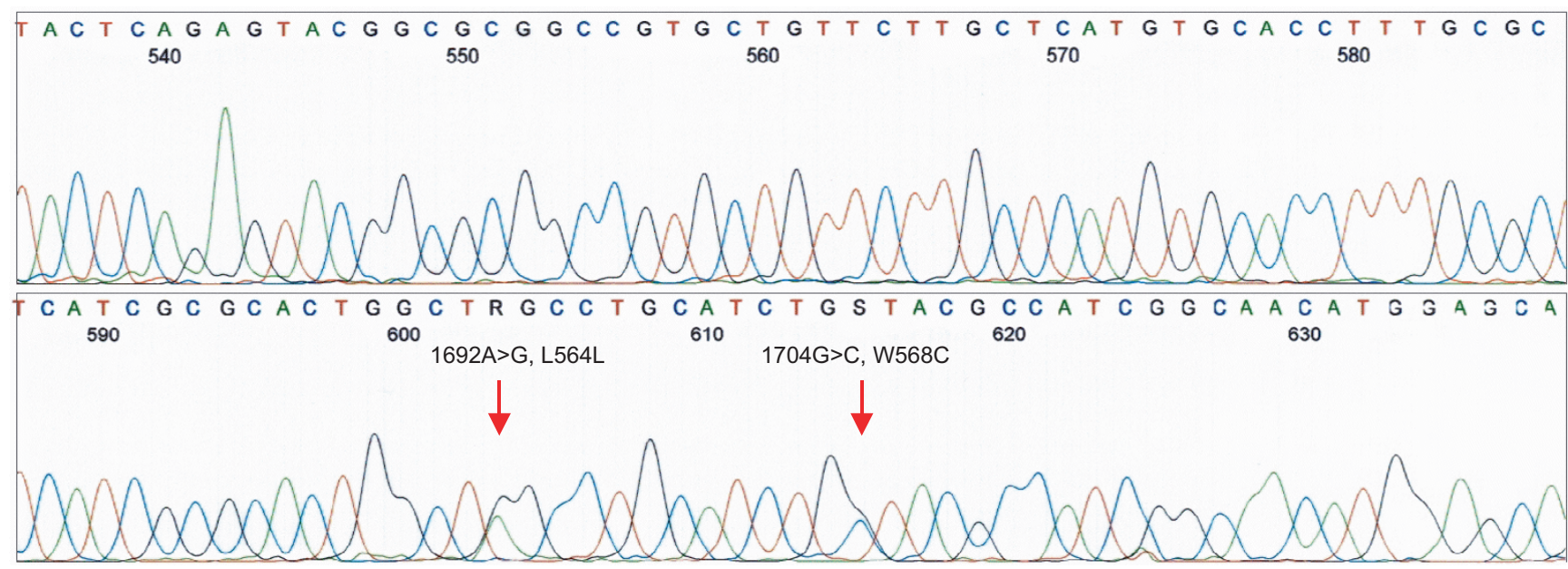

Fig. 2. LQT2 mutation detection using whole blood RNA: cDNA sequence of $K C N H 2$, nucleotides 1624-1727, showing a common SNP, 1682A $>$ G, and a mutation previously associated with LQTS, 1704G >C (W568C).

all 3 genotypes at this locus, with 100\% concordance between RNA- and DNA-derived sequences (Fig. 3).

We then genotyped MYBPC 3 in a patient with a family history of cardiomyopathy and echocardiographic evidence of severe left ventricular hypertrophy localized to the septum and anterior wall. Whole blood RNA analysis revealed this patient to have a previously reported mutation, $1505 \mathrm{G}>\mathrm{A}$ (R502Q). ${ }^{25}$ Initial RNA analysis detected only the mutant $1505 \mathrm{G}>\mathrm{A}$ sequence; however, both mutant and wild type alleles were observed in the corresponding DNA sequence, and we concluded that the proband is heterozygous for this autosomal dominant mutation, similar to the previous report. ${ }^{25}$

\section{Marfan syndrome (FBN1)}

Mutations in FBN1 have been associated with MFS, a disease characterized by multiple connective tissue abnormalities, in-

RNA
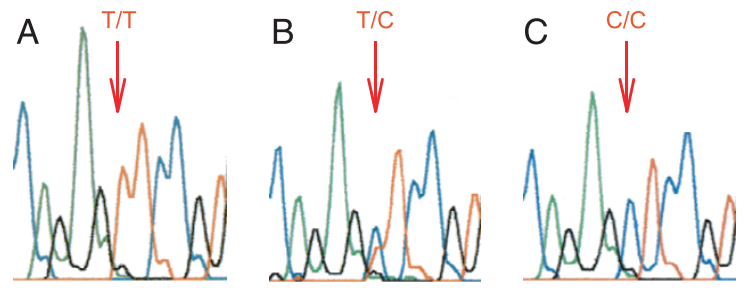

DNA
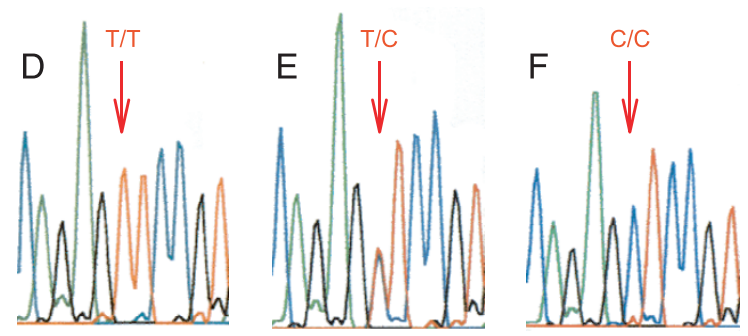

Fig. 3. $M Y B P C 3$ SNP detection using whole blood RNA: Concordance between RNAand DNA-determined genotypes for a SNP (3288A $>$ G, E1096E, rs1052373) in exon 31 of MYBPC3. All sequences are antisense; (A-C) RT-PCR sequences, (D-F) genomic sequences. Panels A and D, B and E, and C and F are from 3 unrelated subjects. Arrows denote the polymorphic residue. cluding lethal aneurysms of the ascending aorta. The entire 8.5-kb coding sequence of FBN1 was successfully amplified from whole blood RNA using 7 overlapping nested PCR primer sets (Table 1).

Using whole blood RNA, we detected disease-causing mutations in 2/2 probands suspected of MFS. The first was identified in one of two 17-year-old identical twins, both tall, with arachnodactyly, but no family history of MFS. A novel deletion in exon 39, 4905delC was identified and confirmed by analysis of the corresponding DNA sequence (Fig. 4A,B). The resulting frame shift created a premature stop codon 4 residues after the deletion.

The second proband, a 30-year-old male, had a mild Marfanoid habitus and an aortic root diameter of $4.24 \mathrm{~cm}$. His father had recently undergone a second aortic root replacement for dissection of the ascending aorta, and had a clinical diagnosis of MFS. RNA sequence obtained from this patient was homozygous for loss of all exon 51 nucleotides (Fig. 4C). Sequencing of the corresponding DNA revealed heterozygosity for 2 previously identified variants, one in the intron preceding exon 51, IVS50-64A $>\mathrm{G}$, and another in the coding region, $6354 \mathrm{C}>\mathrm{T}$ (not shown, and Fig. 4D). The $6354 \mathrm{C}>\mathrm{T}$ variant does not change the amino acid sequence (I2118I), but apparently disrupts a splicing enhancer, ${ }^{26,27}$ resulting in an in-frame deletion of exon 51 in the mRNA. Exon 51 sequences encode part of a conserved cysteine-rich domain shared by many transforming growth factor- $\beta$ binding proteins, and its loss could significantly impact fibrillin function.

\section{Cost comparisons}

The potential cost savings associated with whole blood RNA were considered using Marfan Syndrome (FBN1) as an example. A representative laboratory offering this test requires a skin biopsy and an additional fee to expand fibroblasts in culture. ${ }^{28}$ Using our method, the entire coding sequence of $F B N 1$ could be amplified in 2-3 days from $2.5 \mathrm{~mL}$ whole blood, using 7 nested PCR amplifications. This represents a savings of weeks to months of process- 
Table 3

A

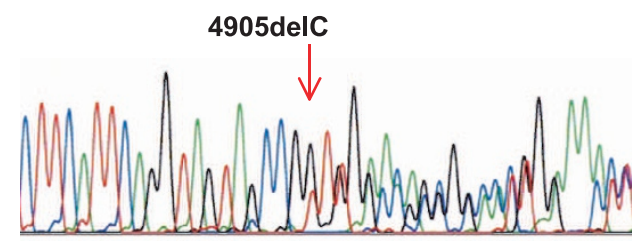

B
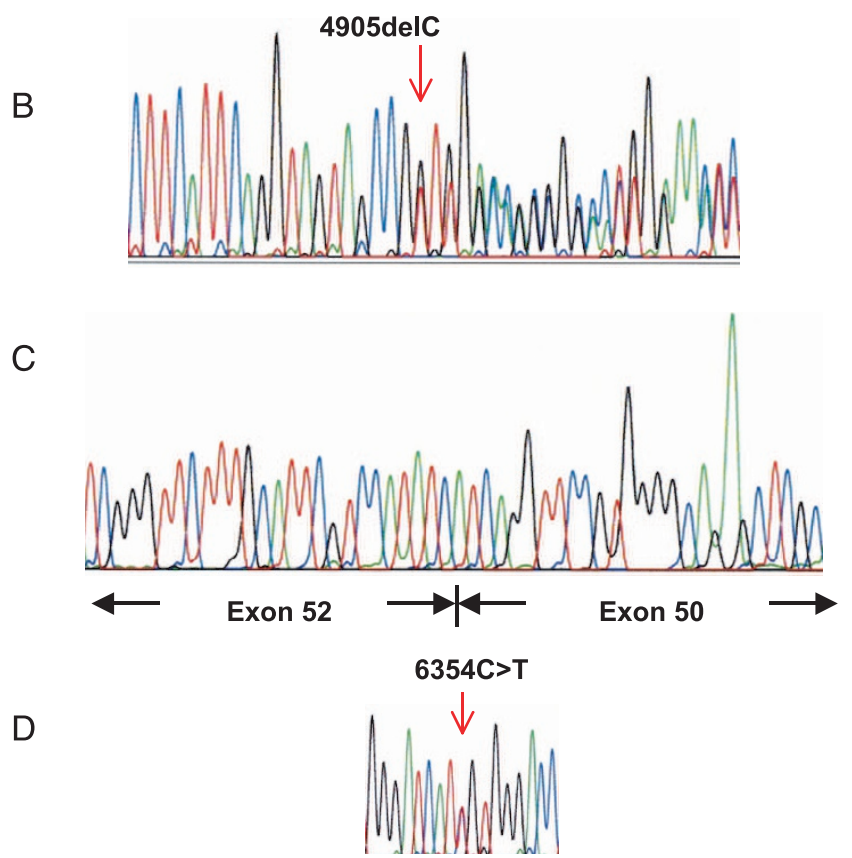

Fig. 4. Whole blood RNA analysis of MFS mutations: (A, B) Proband $1,(C, D)$ Proband 2. (A) Antisense cDNA sequence, nucleotides 4924-4881, of FBN1 mutant 4905delC. Note presence of both alleles. (B) Corresponding DNA sequence. (C) Antisense cDNA sequence showing deletion of $F B N 1$, exon 51. Note absence of wild type allele. (D) DNA sequence of $F B N 1$, exon $51,6354 \mathrm{C}>\mathrm{T}$, the point mutation that disrupts a splicing enhancer.

ing time, and avoids costs associated with skin biopsy and fibroblast culture, typically several hundred dollars per test. Tables 3 and 4 provide a cost analysis of mutation screening in MFS comparing the whole blood RNA method with existing DNA-based protocols as previously described, ${ }^{29}$ using current prices for DNA sequence analysis on a capillary-type apparatus. Again, a significant cost advantage is seen for RNA.

\section{DISCUSSION}

The major new finding in this study is that tissue-restricted mRNAs associated with 3 genetically complex cardiovascular diseases (LQTS, MFS and HCM) can be directly amplified from whole, unfractionated peripheral blood, and used as a robust source for mutation detection. Although mRNA is often cited as the preferred starting material for mutation screening in large genes, obtaining sufficient material for study typically requires either purification of lymphocytes from up to 50 $\mathrm{mL}$ of blood, or skin biopsy followed by several weeks of tissue fibroblast culture..$^{30}$ Even with these approaches, mRNA is not currently used for diagnosis of HCM and LQTS, because ex-
Cost analysis of FBN1 screening using whole blood RNA mutation detection

\begin{tabular}{lrrr}
\hline Method/Procedure & Supplies & Labor & Total \\
\hline RNA extraction & $\$ 12.00$ & $\$ 19.89$ & $\$ 31.89$ \\
DNA extraction & $\$ 5.71$ & $\$ 9.95$ & $\$ 15.66$ \\
RTase reaction & $\$ 6.00$ & $\$ 5.00$ & $\$ 11.00$ \\
PCR, cleanup & $\$ 2.33$ & $\$ 2.32$ & $\$ 32.55$ \\
Sequencing & $\$ 1.75$ & $\$ 1.65$ & $\$ 95.20$ \\
Confirmation (assume 3 exons checked) & & & \\
PCR/cleanup & $\$ 2.33$ & $\$ 2.32$ & $\$ 13.95$ \\
Sequencing & $\$ 1.75$ & $\$ 1.65$ & $\$ 20.40$ \\
Subtotal for entire cDNA screen & & & $\$ 220.65$ \\
PCR licensing fee $(9 \%$ total) & & & $\$ 19.86$ \\
Supervision/analysis $(7$ hrs) & & & $\$ 256.20$ \\
Total cost per patient screened & & $\$ 496.71$ & \\
\hline
\end{tabular}

Labor is calculated at $\$ 19.89 / \mathrm{hr}$ and supervision/analysis time at $\$ 36.60 /$ hour. Sequencing is computed as cost per primer-template $\times 4$ seqs/amplicon $\times 7$ amplicons.

pression of these genes is largely restricted to myocardium, and their mRNA transcripts cannot be reliably obtained from lymphocytes or fibroblast cultures. The method we describe here overcomes both obstacles, taking advantage of observations from recent microarray analyses that quaternary ammonium surfactants can greatly enhance the yield of rare mRNAs from whole blood, and increase the detection of tissue-restricted gene transcripts. ${ }^{31,32}$ We show that cardiovascular-restricted mRNAs can be readily detected in peripheral blood without additional purification steps or cell culture, and then used as starting material for rapid, high-fidelity screening of coding and splicing mutations in genes associated with heart disease.

Sequencing of mRNA screen has the further advantage of being able to reveal functionally significant mutations that could be overlooked by genomic DNA analysis. Splicing consensus sequences are degenerate, and as such, are not unambiguously identifiable from genomic data. It is possible that cDNA sequencing protocols could miss certain large splicing variants that result in extremely large intron inclusions that cannot be amplified by PCR. However, such large inclusions

\section{Table 4}

Cost comparison of mutation detection methods

\begin{tabular}{lcc}
\hline Method & Total for FBN-1 & Total for LQT1/2 \\
\hline SSCP/HA analysis & $\$ 829.98$ & $\$ 461.72$ \\
Enzyme-mediated cleavage analysis & $\$ 1570.34$ & - \\
Direct sequencing of each exon & $\$ 1016.11$ & $\$ 580.21$ \\
Whole Blood RNA & $\$ 496.71$ & $\$ 291.76$ \\
\hline
\end{tabular}

Figures are taken from above cost analysis and from Yuan et al. ${ }^{34}$ with normalization of DNA sequencing costs. Costs per screen assume batch sizes of 15 patient samples for SSCP and 22 samples for enzyme-mediated cleavage analysis. 
are rare, since cryptic splice sites are frequently activated that limit the size of the intronic material included. On the other hand DNA sequencing will inevitably miss certain splicing mutations, such as those within remote or unknown splicing enhancers. This was the case with the FBN1 mutation described here $(6354 \mathrm{C}>\mathrm{T})$ which was a synonymous base substitution remote from a splice junction, and could only have been identified as a splicing mutation by examining RNA directly.

\section{Whole blood RNA cost advantages and comprehensiveness}

As shown in Tables 3 and 4, whole blood RNA can be used to identify MFS mutations at a substantial cost advantage over existing methods; this advantage should further increase as DNA sequencing becomes less expensive. The use of whole blood RNA also saves time, as it can provide a complete initial mutation screen for any of the genes described here in less than a week. A well-equipped lab would require almost twice as long to perform the comparable DNA-based assays. Finally, whole blood RNA approach improves the logistics of screening. Almost all DNA-based assays require multiple samples and controls to be processed simultaneously for proper data interpretation, and to achieve cost efficiency. In contrast, the use of whole blood RNA is equally robust for one or multiple samples, and hence is particularly cost-effective when sample numbers are low.

Napolitano et al. recently described a hierarchical screening strategy for streamlining conventional DNA diagnosis of LQTS, by targeting 64 codons that have been found mutated more than once. ${ }^{3}$ While representing an important advance, the method captured only $58 \%$ of probands carrying a mutation in their study, and would have identified smaller percentages $(39 \%$ and $33 \%)$ of patients reported in two other large series. ${ }^{5,6} \mathrm{~A}$ similar proportion of the estimated $4.5 \%$ of patients with more than one mutation would also be missed. For this reason, a more comprehensive sequencing approach may be necessary when a complete risk assessment is needed. The method we describe here can serve this need by providing complete determination of all protein-coding sequences at relatively low cost.

Our method offers equal or greater advantages for diagnosis of Marfan Syndrome and HCM. The major causative gene for MFS, FBN1, covers over $200 \mathrm{~kb}$ of DNA with more than 600 reported mutations. Currently available RNA-based approaches to this gene require weeks of fibroblast culture, adding greatly to the time and expense of testing; this step is obviated by use of whole blood RNA. For hypertrophic cardiomyopathy, detection and direct sequencing of cardiac-specific myosin binding protein- $\mathrm{C}$, comprising more than $50 \%$ of known HCM mutations, can be performed efficiently using the same approach.

\section{Applicability of whole blood RNA testing in other disorders}

We predict that substantial efficiencies could be realized by adapting this method to other disorders involving multiple genetic loci and/or large, multi-exon genes. An obvious example is ARVD, a rare but lethal cardiomyopathy associated with mutations in one of the largest genes in the genome, the cardiac ryanodine receptor (ARVD2) (RYR2, 105 exons), ${ }^{33}$ and with plakophilin 2 (ARVD9) (PKP2, 14 exons). ${ }^{34}$

Using RNA from purified or transformed lymphocytes, others have successfully amplified mRNA encoding beta-myosin heavy chain (MYH7), one of the proteins mutated in $\mathrm{HCM},{ }^{14}$ as well as genes involved in cystic fibrosis (CFTR), ${ }^{35}$ Duchenne muscular dystrophy $(D M D),{ }^{36}$ and malignant hyperthermia $(R Y R 1) .{ }^{37}$ Differences in gene expression patterns between purified or transformed lymphocytes and unfractionated whole blood cells ${ }^{38}$ may actually favor the detection of certain transcripts. ${ }^{14,15}$ On the other hand, using whole blood RNA, we have successfully amplified mRNA from multiple genes not previously accessible to RNA sequencing, including those linked to LQTS/Brugada syndrome (SCN5A), ARVD (PKP2), dilated cardiomyopathy (lamin A/C, $L M N A$ ) and Barth Syndrome (tafazzin, TAZ; our unpublished data). These findings represent a useful starting observation for future technical improvements.

\section{Potential limitations}

Several technical issues should be considered in applying whole blood RNA sequencing, indeed any RNA-based method, to clinical diagnostics. Tissue-specific splicing could generate alternative transcripts in the test material that are not present in the target tissue, creating the appearance of exon-skipping or insertion mutations. We saw no evidence for this in the genes studied here, although many muscle transcripts are alternatively spliced, and these splicing patterns may not be preserved in heterologous cell types. ${ }^{39}$ Nonsense-mediated mRNA decay ${ }^{48}$ which leads to degradation of transcripts with premature termination codons, could selectively deplete mutant RNA. However, this process is rarely complete, so that the mutant transcript is usually still detectable albeit at reduced levels. Consistent with this, we found that transcripts for both mutant and wild type alleles of the truncation mutation in FBN1, 4905delC, were nearly equally abundant. On two other occasions, only one allele from the gene of interest could be detected (one each for MYBPC 3 and FBN1), and in both cases the mutant allele was preferentially amplified. Although we cannot presently explain this finding, processes such as imprinting, allelic variation in expression, ${ }^{40}$ inadvertent allele-specific PCR, ${ }^{41}$ or preferential amplification ${ }^{42}$ could lead to this result, and to a spurious homozygous genotype. Further analysis of the rate and cause of allelic dropout will be useful to guide further technical improvements in this method.

\section{CONCLUSIONS}

Our findings indicate that whole blood RNA sequencing can be a simple and convenient alternative to SSCP or DHPLC for missense mutation screening, and is inherently better for detection of splicing errors. Indeed, the use of whole blood RNA can replace these technologies as a robust initial screen of all coding regions of the 4 genes described here, followed by conventional DNA sequencing. Our limited data do not permit a quantitative determination of sensitivity or specificity. However, since we were able to detect mutations at frequencies similar to those reported for each 
of these diseases, our data support the view that a diagnostic approach that begins with RNA testing may ultimately prove to have a sensitivity comparable to other mutation detection approaches such as SSCP and DHPLC.

As summarized recently, ${ }^{3}$ prognosis and therapeutic response in LQTS are each strongly predicted by mutation locus. The risk of cardiac arrhythmias and sudden death can also be strongly influenced by genotype in HCM. ${ }^{43}$ In each of these conditions, genetic information may be crucial in establishing the clinical diagnosis, particularly in presymptomatic or sporadic disease, and in adult patients without a positive family history. ${ }^{30,44,45}$ As an added benefit, increasing the pool of genotype information will further improve understanding of genotype-phenotype relationships. ${ }^{46}$ Our approach can reduce some of the practical barriers to DNA mutation screening, and can be immediately useful in research laboratories.

Additional studies will be needed to determine the appropriate place of RNA screening in clinical laboratories. Screening methods are often used in advance of DNA sequencing; reasons include the size and number of genes that need to be sequenced, the availability of labor and instrumentation required to achieve this, and the likelihood of diagnostic certainty within an affordable cost range. Screening tests have the potential to reduce the average labor and time required to identify a mutation, even when negative results are further pursued by DNA sequencing. Total costs for testing will depend greatly on the extent to which negative results are subjected to further testing, factoring in sequencing costs, pretest probability, and the desire for certainty. Our method adds another option to the menu of diagnostic prescreening tools that could have an impact on the logistics of DNA testing, increasing access to genetic testing and improving clinical management for these and other multi-gene disorders. In turn, a demonstrable health impact for genetic testing in these disorders could be persuasive for insurers. ${ }^{47}$

\section{ACKNOWLEDGMENTS}

This work was funded by grants from the Miami Heart Research Institute (NHB and RJM), the National Institutes of Health (R-01-HL71094, NHB) and the Fourjay Foundation, Willow Grove, PA. We are grateful to Katherine Lee and Fanny Morales for their technical assistance in these studies, and to Drs. Lisa Baumbach, Paul Kurlansky and Karl Muench for constructive comments during the preparation of this paper, and to Helen Travers for patient management and counseling. Drs. Ming-Lon Young, Grace Wolff, Paulo Rusconi and Rafael Sequeira provided referrals for several of the subjects in the study.

\section{References}

1. Antzelevitch C, et al. Molecular biology and cellular mechanisms of Brugada and long QT syndromes in infants and young children. J Electrocardiol 2001;34:177-181.

2. Arking DE, Chugh SS, Chakravarti A, Spooner PM, et al. Genomics in sudden cardiac death. Circ Res 2004;94:712-723.

3. Napolitano C, Priori S, Schwartz PJ, Bloise R, et al. Genetic testing in the Long QT Syndrome. JAMA 2005;294:2975-2980.
4. Dietz HC, Cutting GR, Pyeritz RE, Maslen CL, et al. Marfan syndrome caused by a recurrent de novo missense mutation in the fibrillin gene. Nature 1991;352:337-339.

5. Tester DJ, Will ML, Haglund CM, Ackerman MJ, et al. Compendium of cardiac channel mutations in 541 consecutive unrelated patients referred for long QT syndrome genetic testing. Heart Rhythm 2005;2:506-517.

6. Splawski I, Shen J, Timothy KW, Lehmann MH, et al. Spectrum of mutations in long-QT syndrome genes. KVLQT1, HERG, SCN5A, KCNE1, and KCNE2. Circulation 2000;102:1178-1185.

7. Keating MT, Sanguinetti MC. Molecular and cellular mechanisms of cardiac arrhythmias. Cell 2001;104:569-580.

8. Mohler PJ, Schott JJ, Gramolini AO, Dilly KW, et al. Ankyrin-B mutation causes type 4 long-QT cardiac arrhythmia and sudden cardiac death. Nature 2003;421:634-639.

9. Burkett EL, Hershberger RE. Clinical and genetic issues in familial dilated cardiomyopathy. J Am Coll Cardiol 2005;45:969-981.

10. Seidman JG, Seidman C. The genetic basis for cardiomyopathy: from mutation identification to mechanistic paradigms. Cell 2001;104:557-567.

11. Van Driest SL, Ellsworth EG, Ommen SR, Tajik AJ, et al. Prevalence and spectrum of thin filament mutations in an outpatient referral population with hypertrophic cardiomyopathy. Circulation 2003;108:445-451.

12. Halliday DJ, Hutchinson S, Lonie L, Hurst JA, et al. Twelve novel FBN1 mutations in Marfan syndrome and Marfan related phenotypes test the feasibility of FBN1 mutation testing in clinical practice. J Med Genet 2002;39:589-593.

13. Sarkar G, Sommer SS. Access to a messenger RNA sequence or its protein product is not limited by tissue or species specificity. Science 1989;244:331-334.

14. Rosenzweig A, Watkins H, Hwang DS, Miri M, et al. Preclinical diagnosis of familial hypertrophic cardiomyopathy by genetic analysis of blood lymphocytes. $N$ Engl J Med 1991;325:1753-1760.

15. Thierfelder L, Watkins H, MacRae C, Al E. Alpha-tropomyosin and cardiac troponin T mutations cause familial hypertrophic cardiomyopathy: a disease of the sarcomere. Cell 1994;77:701-712.

16. Andersen PS, Havndrup O, Bundgaard H, Larsen LA, et al. Genetic and phenotypic characterization of mutations in myosin-binding protein C (MYBPC3) in 81 families with familial hypertrophic cardiomyopathy: total or partial haploinsufficiency. Eur J Hum Genet 2004;12:673-677.

17. Wang J, Robinson JF, Khan HM, Carter DE, et al. Optimizing RNA extraction yield from whole blood for microarray gene expression analysis. Clin Biochem 2004;37:741-744.

18. Feezor RJ, Baker HV, Mindrinos M, Hayden D, et al. Whole blood and leukocyte RNA isolation for gene expression analyses. Physiol Genomics 2004;19:247-254.

19. Jiang M, Tseng-Crank J, Tseng GN. Suppression of slow delayed rectifier current by a truncated isoform of KvLQT1 cloned from normal human heart. J Biol Chem 1997;272:24109-24112.

20. London B, Trudeau MC, Newton KP, Beyer AK, et al. Two isoforms of the mouse ether-a-go-go-related gene coassemble to form channels with properties similar to the rapidly activating component of the cardiac delayed rectifier $\mathrm{K}+$ current. Circ Res 1997;81:870-878.

21. Jongbloed R, Marcelis C, Velter C, Doevendans P, et al. DHPLC analysis of potassium ion channel genes in congenital long QT syndrome. Hum Mutat 2002;20:382-391.

22. Zareba W, Moss AJ, Sheu G, Kaufman ES, et al. Location of mutation in the KCNQ1 and phenotypic presentation of long QT syndrome. J Cardiovasc Electrophysiol 2003; 14:1149-1153.

23. Gene Connection for the Heart: Fondazione Salvatore Maugeri, 2006. http:// pc4.fsm.it:81/cardmoc.

24. Richard P, Charron P, Carrier L, Ledeuil C, et al. Hypertrophic cardiomyopathy: distribution of disease genes, spectrum of mutations, and implications for a molecular diagnosis strategy. Circulation 2003;107:2227-2232.

25. Niimura H, Bachinski LL, Sangwatanaroj S, Watkins H, et al. Mutations in the gene for cardiac myosin-binding protein $\mathrm{C}$ and late-onset familial hypertrophic cardiomyopathy. N Engl J Med 1998;338:1248-1257.

26. Liu W, Qian C, Francke U. Silent mutation induces exon skipping of fibrillin-1 gene in Marfan syndrome. Nat Genet 1997;16:328-329.

27. Caputi M, Kendzior Jr. RJ, Beemon KL. A nonsense mutation in the fibrillin-1 gene of a Marfan syndrome patient induces NMD and disrupts an exonic splicing enhancer. Genes Dev 2002;16:1754-1759.

28. Marfan Syndrome - Mutation detection: Center for Genetic Testing at Saint Francis, 2006 http://www.sfh-lab.com/marfan\%20direct.htm.

29. Yuan B, Thomas JP, von Kodolitsch Y, Pyeritz RE. Comparison of heteroduplex analysis, direct sequencing, and enzyme mismatch cleavage for detecting mutations in a large gene, FBN1. Hum Mutat 1999;14:440-446.

30. Toudjarska I, Kilpatrick MW, Lembessis P, Carra S, et al. Novel approach to the molecular diagnosis of Marfan syndrome: application to sporadic cases and in prenatal diagnosis. Am J Med Genet 2001;99:294-302. 
31. UniGene: National Center for Biotechnology Information, NIH, 2006. http://www. ncbi.nlm.nih.gov/entrez/query.fcgi?db= unigene.

32. Gene Expression Omnibus: National Center for Biotechnology Information, 2006. http://www.ncbi.nlm.nih.gov/geo.

33. Tiso N, Stephan DA, Nava A, Bagattin A, et al. Identification of mutations in the cardiac ryanodine receptor gene in families affected with arrhythmogenic right ventricular cardiomyopathy type 2 (ARVD2). Hum Mol Genet 2001;10:189-194.

34. Gerull B, Heuser A, Wichter T, Paul M, et al. Mutations in the desmosomal protein plakophilin-2 are common in arrhythmogenic right ventricular cardiomyopathy. Nat Genet 2004;36:1162-1164.

35. Fonknechten N, Chelly J, Lepercq J, Kahn A, et al. CFTR illegitimate transcription in lymphoid cells: quantification and applications to the investigation of pathological transcripts. Hum Genet 1992;88:508-512.

36. Roberts RG, Bobrow M, Bentley DR. Point mutations in the dystrophin gene. Proc Natl Acad Sci U S A 1992;89:2331-2335.

37. Kraev N, Loke JC, Kraev A, MacLennan DH. Protocol for the sequence analysis of ryanodine receptor subtype 1 gene transcripts from human leukocytes. Anesthesiology 2003;99:289-296.

38. Whitney AR, Diehn M, Popper SJ, Alizadeh AA, et al. Individuality and variation in gene expression patterns in human blood. Proc Natl Acad Sci U S A 2003;100:1896-1901.

39. Breitbart RE, Andreadis A, Nadal-Ginard B. Alternative splicing: a ubiquitous mechanism for the generation of multiple protein isoforms from single genes. Ann Rev Biochem 1987;56:467-495.
40. Hutchinson S, Furger A, Halliday D, Judge DP, et al. Allelic variation in normal human FBN1 expression in a family with Marfan syndrome: a potential modifier of phenotype? Hum Mol Genet 2003;12:2269-2276.

41. Tester DJ, Cronk LB, Carr JL, Schulz V, et al. Allelic dropout in long QT syndrome genetic testing: a possible mechanism underlying false-negative results. Heart Rhythm 2006;3:815-821.

42. Liu Q, Thorland EC, Sommer SS. Inhibition of PCR amplification by a point mutation downstream of a primer. Biotechniques 1997;22:292-298.

43. Arad M, Seidman JG, Seidman CE. Phenotypic diversity in hypertrophic cardiomyopathy. Hum Mol Genet 2002;11:2499-2506.

44. Priori SG, Schwartz PJ, Napolitano C, Bloise R, et al. Risk stratification in the long-QT syndrome. N Engl J Med 2003;348:1866-1874.

45. Watkins H, Thierfelder L, Hwang DS, McKenna W, et al. Sporadic hypertrophic cardiomyopathy due to de novo myosin mutations. J Clin Invest 1992;90:16661671 .

46. Anderson ME, Al-Khatib SM, Roden DM, Califf RM, et al. Cardiac repolarization: current knowledge, critical gaps, and new approaches to drug development and patient management. Am Heart J 2002;144:769-781.

47. Grosse SD, Khoury MJ. What is the clinical utility of genetic testing? Genet Med 2006;8:448-450.

48. Neu-Yilik G, Gehring NH, Hentz MW, Kulozik AE. Nonsense-mediated mRNA decay: from vacuum cleaner to Swiss army knife. Genome Biol 2004;5: Article 218 (Available at http://genomebiology.com/2004/5/4/218). 